\title{
THE EFFECT OF NOVEL AND FAMILIAR PREDATOR CUES ON PREY VIGILANCE AND FORAGING BEHAVIORS IN THE GREATER KHINGAN MOUNTAINS, INNER MONGOLIA, CHINA
}

\author{
MPEMBA, H. ${ }^{1 \#}-$ FAN Y. ${ }^{1 \#}-$ MACLEOD, K. J. ${ }^{2,3}-$ WEN, D. ${ }^{1}-$ JIANG, G. ${ }^{1 *}$ \\ ${ }^{1}$ Feline Research Center of State Forestry and Grassland Administration, College of Wildlife \\ Resources, Northeast Forestry University \\ 26 Hexing Road, Harbin, Heilongjiang 150040, P.R. China
}

${ }^{2}$ Department of Ecosystem Science and Management, Pennsylvania State Univ., Forest

Resources Building, University Park, PA 16802, USA

${ }^{3}$ Department of Biology, Lund University, Sölvegatan 37, 22362 Lund, Sweden

${ }^{\#}$ Contributed equally

${ }^{*}$ Corresponding author

e-mail: jgshun@126.com; phone: +8613895712963

(Received 23 $3^{\text {rd }}$ Feb 2019; accepted $1^{\text {st }}$ May 2019)

\begin{abstract}
During periods of predation risk, prey adopt antipredator behaviours to maximise chances of survival, such as increased vigilance, reduced foraging time, shifting to safe habitat, and group formation. To effectively balance resource acquisition and antipredator behavior, prey animals make use of cues within their environment that provide them accurate information about the realistic threat of predation. Using camera traps, we tested vigilance and feeding behavioural responses of two naturally occurring ungulate species roe deer and moose to cues from naturally occurring brown bear and novel Amur tiger predators. We found that roe deer and moose vigilance and feeding behaviours were not affected by either visual or olfactory cues from predators, suggesting that ungulates in this system do not respond differently to novel predator cues. There are a number of potential explanations for this surprising lack of response to any predator cues: a) habituation to uninformative cues is important; $b$ ) ungulates might have relied more heavily on other cue types, such as auditory cues, or cues in combination; and, c) constraints on dispersal and/or resources may result in prey being forced to remain in high risk food patches, and continued prioritization of feeding over vigilance. We therefore, recommend that in the future studies regarding cues should involve a combination of cues at a similar location to increase predation risk to the animals to maximise prey response. To our knowledge, this is the first study to lay out the foundation of the ecological influences of captive Amur tiger on prey behaviors in the wild environment.
\end{abstract}

Keywords: predators, ungulates, fear ecology, camera trap, antipredator, hanma, vigilance, foraging

\section{Introduction}

Under predation risk, prey adopt predation avoidance behaviours to maximise their chances of survival (Blumstein, 2006), such as increased vigilance, change of foraging time, shifting to safe habitat, and group formation (Creel and Christianson, 2008; Li et al., 2011; Kuijper et al., 2014). Vigilance behaviors - which can be explained as the time a prey animal spends being alert, actively scanning for predators, and fleeing (Brown and Kotler, 2004; Creel and Christianson, 2008; Creel et al., 2014) - help prey animals adjust to predation risk (Li et al., 2011) through prioritizing predator recognition (Brown and Kotler, 2004). Predation risk determines the habitat pattern to be used by most prey species (Laundré et al., 2001; Hernández and Laundré, 2005), due to the fact that the presence of large predators builds a "landscape of fear" (Laundré et 
al., 2001) meaning that prey perceive risk differently in different habitats and act and distribute themselves accordingly (Hernández and Laundré, 2005; Brook et al., 2012).

Prey species trade off activities such as foraging, moving between patches, mating, and vigilance behaviours - how this unfolds can have substantial effects on prey species life history trajectories (Lima and Bednekoff, 1999; Eccard et al., 2017). This balance of behaviours is likely to be skewed more towards antipredator behaviours in high predation risk habitat, with vigilance taking a higher priority (Blumstein, 2003). The optimal foraging theory states that under high risk conditions, foraging time is minimised (Lima and Bednekoff, 1999; Eccard and Liesenjohann, 2008). For example, under high predation pressure from predators like wolves (Canis lupus) and Lynx (Lynx lynx) (Eccard et al., 2017), ungulate species decrease foraging and increase vigilance (Eccard et al., 2017). This shows how fear effects can shape individual behaviours and even community significantly even than direct killing (Creel and Christianson, 2008; Creel et al., 2014).

In order to effectively balance resource acquisition and antipredator behavior (Brown and Cowan, 2000; Brown and Kotler, 2004), prey animals make use of cues within their environment that provide them accurate information about the realistic threat of predation (Hemmi and Pfeil, 2010). For example, experimental manipulation of apex predator cues, such as visual and odor cues or both, reduces foraging behaviors carried out by the dottyback fish, Pseudochromis fuscus (Palacios et al., 2016). In most cases predator odour cue results in minimized foraging activity (Nersesian et al., 2012) or total prey avoidance of the area (Apfelbach et al., 2005; Kats and Dill, 2016). In mammalian species, the use of predator odour cues may be especially prevalent given the importance of olfactory cue use in intraspecific communication (Wikenros et al., 2017). For example, roe deer Capreolus pygargus respond to lynx odour (urine) cue by either staying vigilant or avoiding predation risk areas (Eccard et al., 2017). In terms of informational content, however, predator visual cues may elicit stronger responses because they reveal immediate risk (Noell, 2013; Chamaillé-Jammes et al., 2014).

To improve our understanding of how the ecological community is structured, it is wise to learn how prey species assess and respond to risk from predators (Blumstein et al., 2000). Our previous work (submitted) has shown that predator cues alter the incidence of ungulate species in a landscape. However, ungulates do still exist in landscapes where perceived predation risk is high (i.e., in the presence of predator cues). Here, we test if these predator cues (visual and odour) result in altered prey behavior. We hypothesise that in the presence of cues, ungulates will display a) increased vigilance, and b) reduced foraging, in line with the findings of previous studies (Bridges, 2002; Brown and Kotler, 2004; Apfelbach et al., 2005; Nersesian et al., 2012; Creel et al., 2014; Cremona et al., 2014; Beauchamp, 2015; Olson et al., 2015; Eccard et al., 2017). We also test whether there is a difference in ungulate response to familiar and novel predators (Brown bear and Amur tiger, respectively). Prey that is not familiar with a predator (novel predator) due to lack of experience or non-evolutionary history might not respond or show a weak response (Banks and Dickman, 2007; Smith et al., 2008; Sih et al., 2010). Therefore, since there is no evidence for Amur tiger to have historically lived in the study area we would expect no or weak response from the prey to tiger cues. Since there are plans to train and rewild the Amur tiger (Wang et al., 2018), it is useful to know well about its ecological influence on prey foraging and vigilance behaviors. Lastly, we also test differences in response to cues between ungulates of different size classes (roe deer, and moose). As it is suggested that small 
and large body sizes mammal respond differently to predation risk (Riginos, 2015; Rogers, 2016); hence, we predict size-differences in predator response. This study will help our understanding of whether and how the presence of predator cues in an environment may further influence ungulate behavioural trade-offs beyond the differential use of the landscape, with possible consequences for fitness and population dynamics.

\section{Material and methods}

\section{Study area}

The study was conducted in Hanma National Nature Reserve, near to a small town of Genhe, Inner Mongolia, North East China (Fig. 1) $\left(51^{\circ} 20^{\prime} 02^{\prime \prime}-51^{\circ} 49^{\prime} 48^{\prime \prime} \mathrm{N}\right.$, $122^{\circ} 23^{\prime} 34^{\prime \prime}-122^{\circ} 52^{\prime} 46^{\prime \prime} \mathrm{E}$ ) (Guo et al., 2017) between July 2016 and July 2017. The National Forestry Administration Unit owns the reserve which is located in the Greater Khingan Mountains, being run as a nature reserve. Hanma has a total area of $1073 \mathrm{~km}^{2}$, with no or very low human disturbance due to its distance from human settlements (Zhai Penghui, 2015; Guo et al., 2017). Habitat, vegetation and wildlife composition are described elsewhere (Zhai Penghui, 2015; Guo et al., 2017).

\section{Experimental design and treatments}

\section{Design}

In the current study, we tested the behavioural responses of two naturally occurring ungulate species roe deer (Capreolus pygargus) and moose (Alces alces)) to cues from naturally occurring brown bear (Ursus arctos) and a novel Amur tiger (Panthera tigris tigris) predators. We divided the study site into grids, randomly created using the fishnet method in ArcGIS 9.3 (Krivoruchko, 2011), which encompassed 2 different types of cue treatments.

Three grids contained visual cues: one grid containing cues of Amur tiger, one grid containing cues of brown bear, and a separate control grid. Treatments were kept separate in order to avoid cue treatment at one camera site affecting the behaviour of ungulates at nearby camera sites that may be of different treatments. The grid plot sizes were quantified as $3.2 \mathrm{~km} \times 3.2 \mathrm{~km}$, and each grid had 18 camera traps including control, 54 in total. Note that because brown bears are native in this habitat, we cannot conclusively confirm that our control grids contained no bear cues; however, as bears occur at low density in this area (Guo et al., 2017), we are confident that at least, our treatment increased perceived predator density in this area.

An odour cue experiment was initially designed in the same way (one grid containing tiger odour, and a control grid). However, after arriving at the site, we found some area (parts of the tiger odour cue experiment/group) were flooded with water and others with too big mountains with a dense forest harsh to be accessed. Due to this setback, we redesigned the tiger odour cue experiment with both of the two grids containing both treatment (tiger odour cue) and control in each half (See Figure 1) in order to set each treatment grid with its control over similar environmental conditions. Here, grid plots were smaller in size, i.e. $(1.6 \mathrm{~km} \times 1.6 \mathrm{~km})$ compared to that of visual cues experiment due to the same logistical constraints. Each grid had eight camera traps, i.e. $(8 \mathrm{x}$ tiger feces, $8 \times$ controls) $\times 2$, making a total of 32 camera traps for the odour cue experiment. 
In the assigned grids, we deployed a total of 86 camera traps (LTL ACORN scouting camera; Ltl 5210 5MP \& Ltl 5210A 12MP, and Nighthawk Bestguarder SG-990V infrared sensor trigger self-timer digital camera). Cameras were set at least $1 \mathrm{~km}$ apart, and the positioning for each individual camera was decided based on different animal signs such as trails, droppings and near water sources. We set all the cameras with a video mode to record 20 seconds at an interval of 5 seconds when triggered.

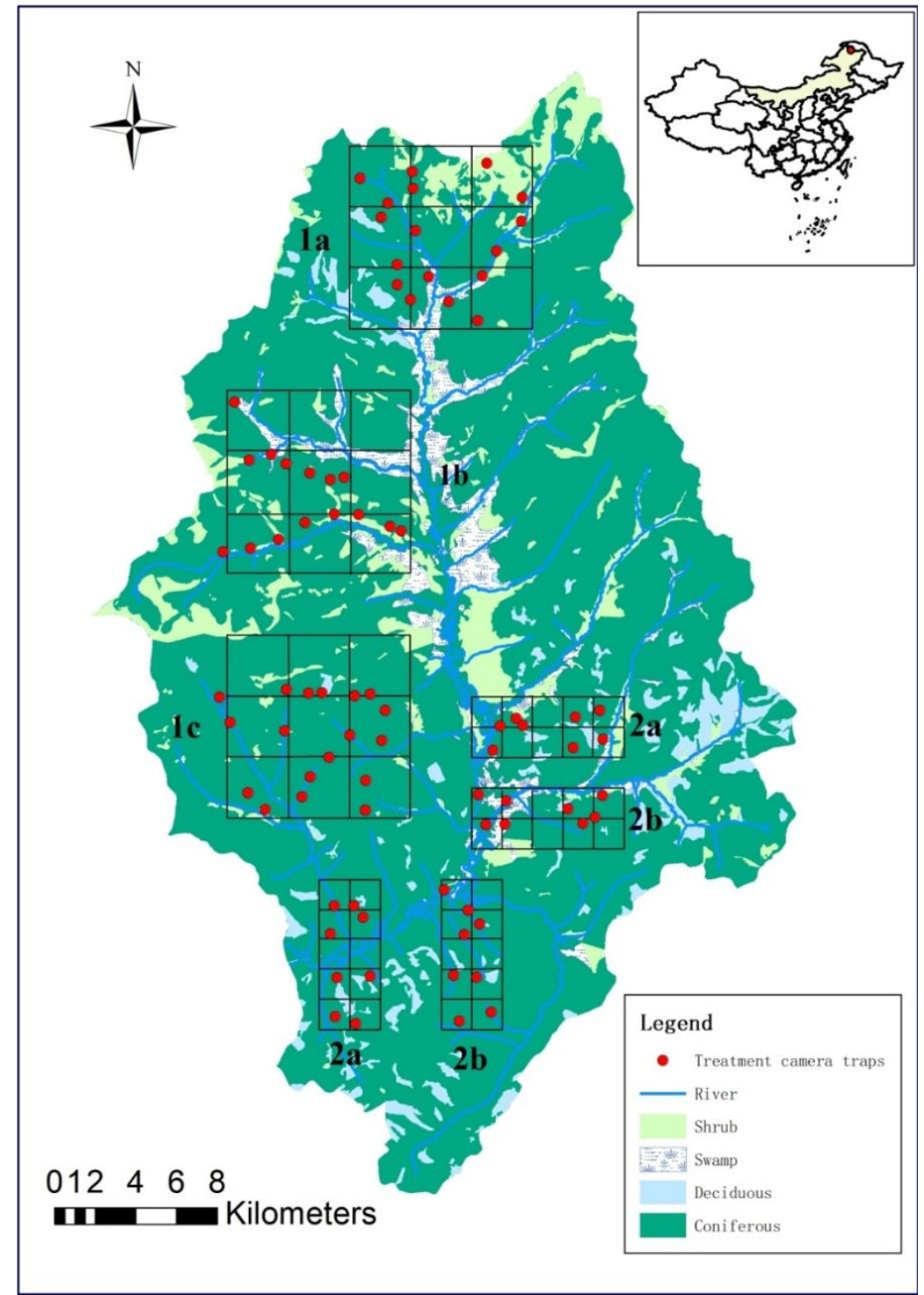

Figure 1. A map indicating the location of the experimental area and different types of surrounding habitats. The number 1 represent visual cue experiment (i.e., la-tiger, $1 b$-bear, 1c-control), and number 2 represent the odour cue experiment (i.e., $2 a$ - tiger, $2 b$-control). Tiger visual (1a) includes a $100 \mathrm{~cm} \times 100$ a $2 \mathrm{D}$ picture of standing tiger printed on a canvas which is tied to two opposite trees, with a camera tied to one of the trees; with everything similar at the bear visual (1c). For the control visual (1c), a canvas similar in settings as tiger and bear visual cues was printed to mimic the environment and tied to two opposite trees with a camera tied to one of the trees to record visitation incidences. The Grids in $2(a \& b)$ represent the tiger order cue experiment, a plastic bottle filled with tiger feces (i.e., 2 a groups) and then a camera tied on a nearby tree to record the visitation rate; the same was done to odour cue control filled with soil ( $2 b)$ groups 


\section{Visual cue experiment}

Predator visual cues (a life-size photo of a standing tiger, bear or vegetation like control were printed on a canvas; Figure 2. following studies by (Li et al., 2011; Fischer et al., 2017) were printed on canvas at a size of $100 \mathrm{~cm} \times 100 \mathrm{~cm}$. The canvas was suspended between two opposite standing trees at each camera site. Cameras were tied $\sim 50 \mathrm{~cm}$ from the ground one of the trees to record animal behaviours (i.e., the camera faced away from the visual cue, in the direction of approaching ungulates).

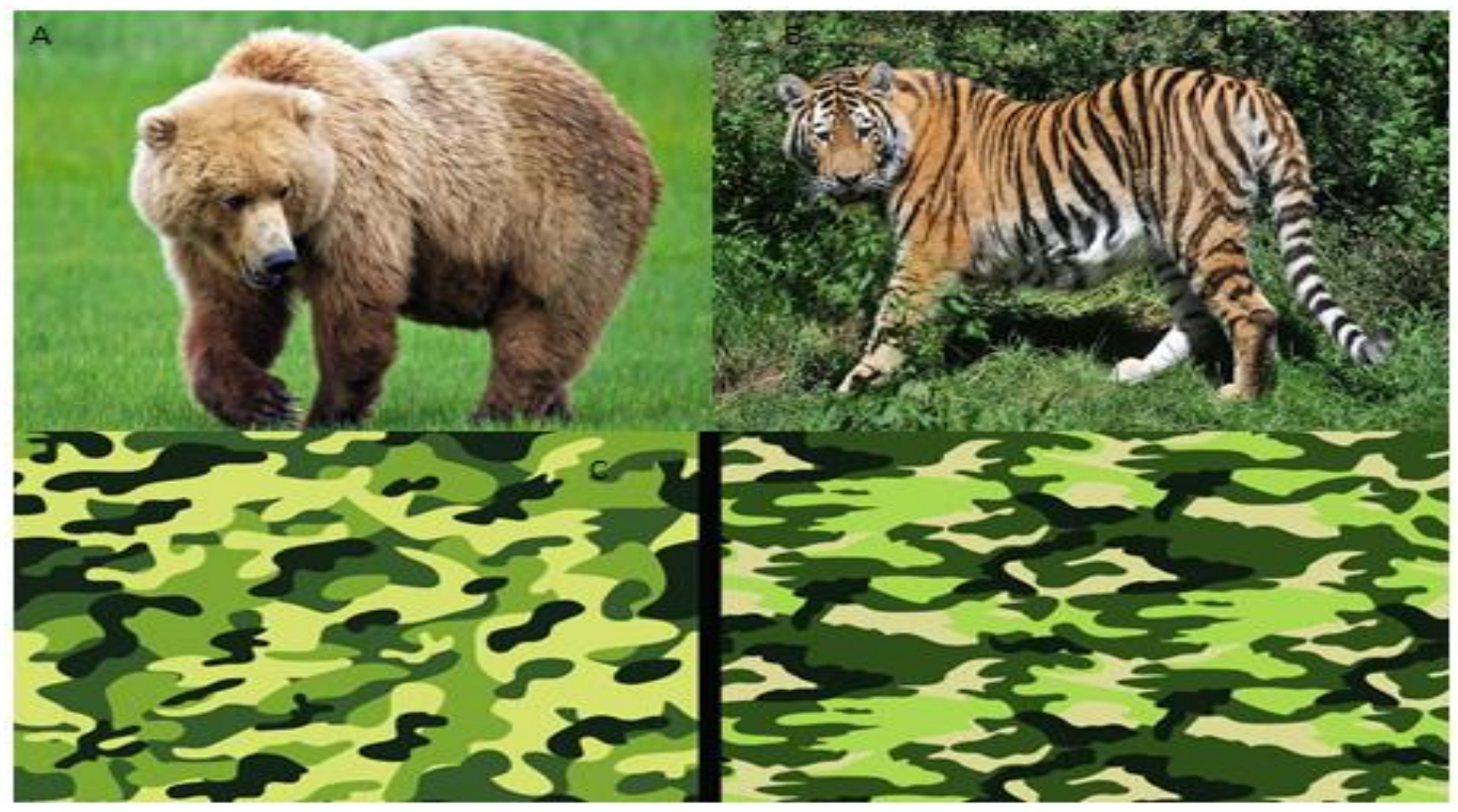

Figure 2. Visual cues treatment and control. A- Is a brown bear photo representing bear visual cue, $B$ - is Amur tiger photo reprinting tiger visual cue, and $C$ - which is vegetation/habitat like photo represent control visual cue. They were both hanged on two different trees and a camera tied on one of the trees to record ungulates behavioral responses

\section{Odour cue experiment}

As predator odour cue, we used Amur tiger fresh feces from Harbin Siberian Tiger Park, transferred into $150 \mathrm{ml}$ plastic bottles (Figure $3 B$ ) which had small holes around to produce the odour. Feces were collected no more than one week before deployment and in the interim stored in laboratory refrigerators at $-20^{\circ} \mathrm{C}$ to avoid quality loss. Bottles were tied to trees $\sim 50 \mathrm{~cm}$ above ground opposite the camera trap and in the focus of the camera to record animal behavioural responses. As a control, we used soil which was filled in the same $150 \mathrm{ml}$ plastic bottles and tied on the tree at the same settings as the odour cues (Figure 3A). Due to unavailability of fresh bear feces, we, unfortunately,, could not involve bear odour cues in this experiment.

\section{Data collection}

Cameras were deployed for 1 year, after which SD cards were collected, and cues were removed. Behavioural data were collected from the resulting videos using focal sampling and all occurrence methodology (Altmann, 1974; Martin et al., 1993; Margulis, 2016). For this study the behavioral data extracted were- vigilance and 
foraging behaviours for ungulates which triggered the camera to record). All recordings which were activated inside 30 minutes of one another and contained similar animals were considered one visit. Ungulate species that were detected included roe deer, musk deer (Cervus elaphus), red deer, wild boar (Sus scrofa), and moose; however, due to low numbers, we only considered roe deer and moose further.

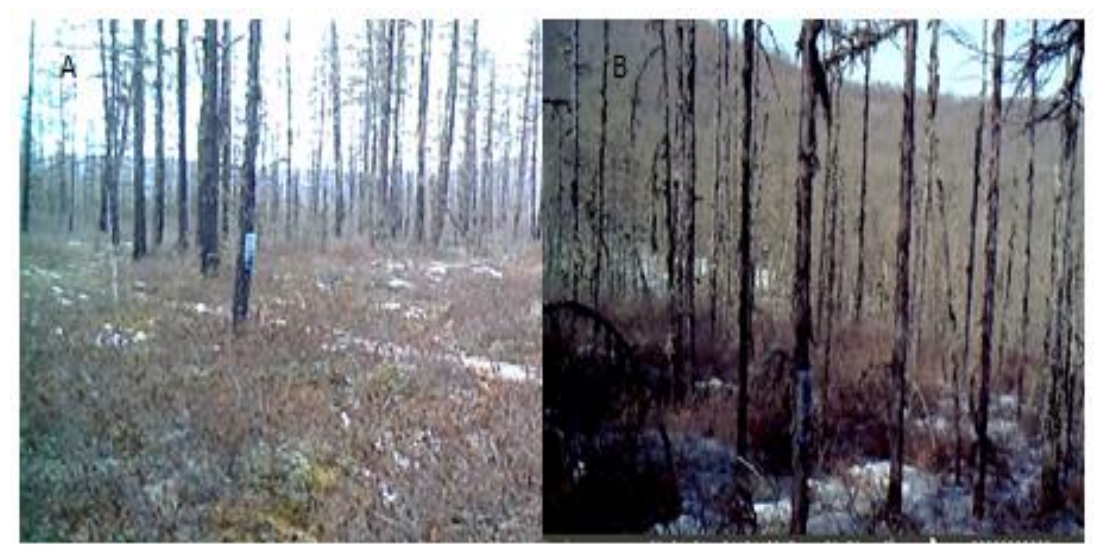

Figure 3. Odour cue treatment and control; A-Represent a plastic bottle (150ml) field with Amur tiger odour cue control (soil), and B is the same bottle filled with Amur tiger odour cue (feces). All the bottles were similar, just differing in contents. The camera was located in front or nearby the bottler to be able to record animal behavioral responses when around the odour cue or control

\section{Behavioral coding, description, and classification}

We classified behaviours into five main components following Heijtel and van Hooft (2014), Meng et al. (2008), and Li et al. (2011), to include vigilance and feeding behaviours (Table 1).

Table 1. Behavioral classification used in this study

\begin{tabular}{|c|c|}
\hline Behavior & Description/definition \\
\hline Vigilant - VG & $\begin{array}{l}\text { Animal keeps a careful watch or looks for possible danger occurrence within the habitat. } \\
\text { Usually, the eyes are wide open. It includes behaviors as stare, stand while head up, smell } \\
\text { while staring, walk while head up, walk while turning head, turn head, turn ears, alert, } \\
\text { stand, listen and turn the body }\end{array}$ \\
\hline Feeding - FD & $\begin{array}{c}\text { The animal is feeding/eating or drinking. It involves behaviors like forage, walk while } \\
\text { foraging, water drinking, and suckling }\end{array}$ \\
\hline Locomotion - LO & $\begin{array}{l}\text { The animal is moving without any accompanying behaviors; it includes actions as walk, } \\
\text { jump, trot, run and swim }\end{array}$ \\
\hline Communication - $\mathrm{CO}$ & $\begin{array}{l}\text { Animal express behaviors that help others to know their presence and also marking their } \\
\text { territories. It includes behaviors like the smell, sniff, walk while smelling, rub and rub } \\
\text { against a tree }\end{array}$ \\
\hline
\end{tabular}

We included other behaviours such as communication and locomotion in separate groups because we did not have explicit predictions about how predator cues might influence these behaviours and because we decided to focus on the foraging/vigilance trade off. Our analyses focused on feeding and vigilance behaviours, as the trade-off between anti-predator behaviour (vigilance) and self-maintenance behaviour (foraging) 
is a key life-history concern in response to predation risk (Brown, 1999). We included other behaviours such as communication and locomotion in separate groups because we did not have explicit predictions about how predator cues might influence these behaviours and because we decided to focus on the foraging/vigilance trade off.

\section{Statistical methods}

From our camera traps, we obtained a total of 193 records from cameras in the visual cues experiment, and 399 records from cameras in the olfactory cues experiment. For the purposes of statistical analyses, we excluded records from species that had too few records overall, or where records were from too few cameras to be representative $(\mathrm{N}=41$ records from musk deer (from only 2 cameras), in the visual cues experiment; $\mathrm{N}=15$ musk deer and $\mathrm{N}=5$ wild boar in the olfactory cues experiment). We also excluded records from moose in the analysis of the visual cues experiment, as all control records were from a total of only 2 cameras. As a result, analyses of the visual experiment consisted of 142 records of roe deer, and analyses of the olfactory cue experiment consisted of 209 records of roe deer and 170 records of moose.

The effects of predator cues (visual and olfactory) on the proportion time ungulates spent being vigilant (as defined in Table 1) and time spent feeding (as defined in Table 1) were tested using generalized linear mixed models using the lme4 package in $\mathrm{R}$ (Team, 2015). For analyses of both the visual and olfactory cue experiments, the proportion of time spent vigilant/feeding was constructed as a paired column (created using the cbind function in R). The paired column containing time spent vigilant/time spent feeding in one column, and total time spent doing other behaviours (i.e., the total time the animal was recorded, minus the time spent vigilant/feeding) as a second column. This allowed us to account for variation in the total time recorded. Experimental treatment (in the case of the visual cue experiment: control, tiger cue, bear cue; in the case of the olfactory cue experiment: control, tiger cue) was set independent variable. Also included was the number of days the camera had been active at the time of recording (i.e., days treatment was in place) (this variable was logged to improve normality and scaling). Camera ID was set as a random term to account for nonindependence of multiple records from the same camera. As the visual cue experiment contained the only deer, species was not included as a variable in this analysis. In the analysis of the olfactory cue experiment, an interaction term treatment*species was included as an explanatory variable to test whether treatment effects differed between species.

\section{Results}

\section{Visual predator cue experiment}

There was no effect of visual predator cue treatments on roe deer vigilance behaviour (treatment $X^{2}{ }_{2}=0.15, \mathrm{P}=0.93$ ), or feeding (treatment $X^{2}{ }_{2}=2.81, \mathrm{P}=0.25$ ) (Figure 4). Post-hoc analysis (Tukey test) revealed that there was no difference in proportion time spent vigilant or feeding specifically between the two predator cue treatments (tiger and bear visual cues: vigilance $\mathrm{Z}=0.08, \mathrm{P}=0.99$; feeding $\mathrm{Z}=-1.55, \mathrm{P}=0.27$ ). Vigilant and feeding behaviours also were not predicted by the length of time (days) the camera and treatment had been in place (days camera activity vigilance: $X^{2}{ }_{1}=2.45, \mathrm{P}=0.12$; feeding $X^{2}{ }_{1}=0.79, \mathrm{P}=0.37$ ). 


\section{Olfactory predator cue experiment}

We observed a significant interactive effect of treatment and species on time investment in vigilance behaviour (treatment*species $X^{2}{ }_{1}=22.8, \mathrm{P}<0.001$ ). Post-hoc analysis (Tukey test) revealed that this effect was driven by roe deer having a higher base vigilance rate (i.e. were more vigilant than moose under the control treatment: $\mathrm{Z}=3.56, \mathrm{P}<0.01)$ but a lower vigilance rate under the predator treatment, tiger odour $(\mathrm{Z}=-3.15, \mathrm{P}<0.01)$ (Figure 5a).
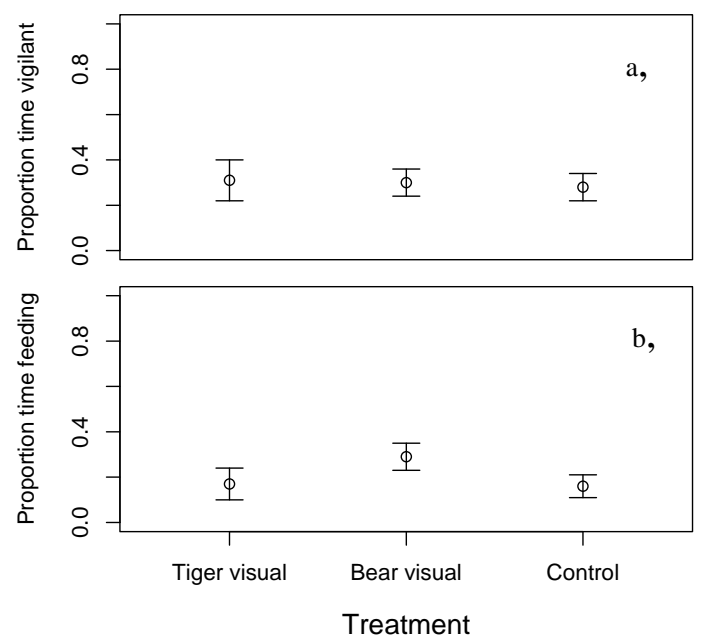

Figure 4. The presence of predator visual cues did not influence time investment in a) vigilance and b) feeding behaviour in roe deer

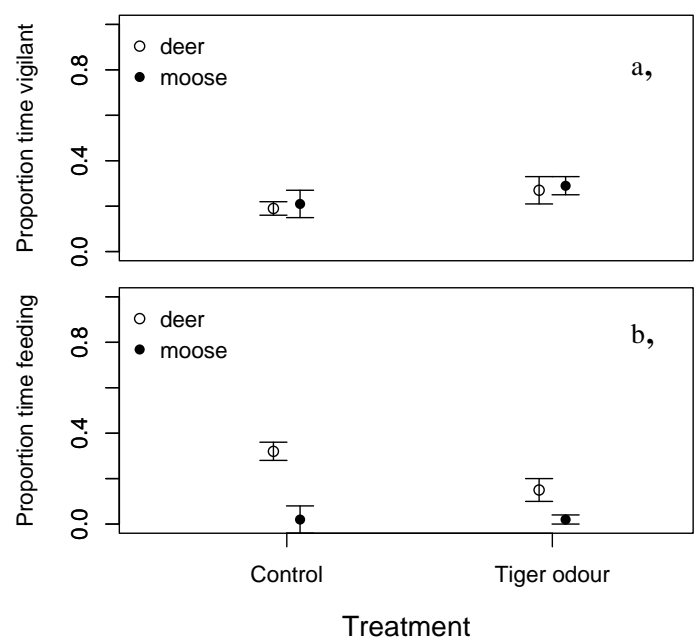

Figure 5. Predicted effects from a model accounting for days of camera activity of predator odour treatment on a) vigilance and b) feeding in roe deer (open circles) and moose (filled circles). Effects of treatment differed significantly between species in both cases, but responses to predator odour within species were not statistically significant in both cases

This interactive result suggests that moose responded more strongly to tiger odour. However, within-species effects of treatment were not significant, according to post-hoc tests (roe deer $\mathrm{Z}=1.05, \mathrm{P}=0.72$; moose $\mathrm{Z}=-2.05, \mathrm{P}=0.17$ ). 
We also observed a significant interactive effect of treatment and species on time investment in feeding (treatment*species $X^{2}{ }_{1}=49.12, \mathrm{P}<0.001$ ) (Figure 5b). Post-hoc analysis (Tukey test) revealed that this effect was driven by differences between roe deer and moose feeding rates under the control treatment (moose feeding rate significantly lower, $\mathrm{Z}=5.94, \mathrm{P}<0.001$ ) (Figure 6). There was no significant difference between roe deer and moose in feeding rates under the predator cue treatment $(Z=-0.3$, $P=0.99)$. Again, within-species effects of treatment were not significant, according to post-hoc tests (roe deer $\mathrm{Z}=1.95, \mathrm{P}=0.21$; moose $\mathrm{Z}=-2.25, \mathrm{P}=0.11$ ).

Both vigilance and feeding behaviours were significantly predicted by the length of time (days) the camera and treatment had been in place (days camera activity, vigilance: $X^{2}{ }_{1}=164.34, \mathrm{P}<0.001$; feeding $\left.X^{2}{ }_{1}=11.86,<0.001\right)$.
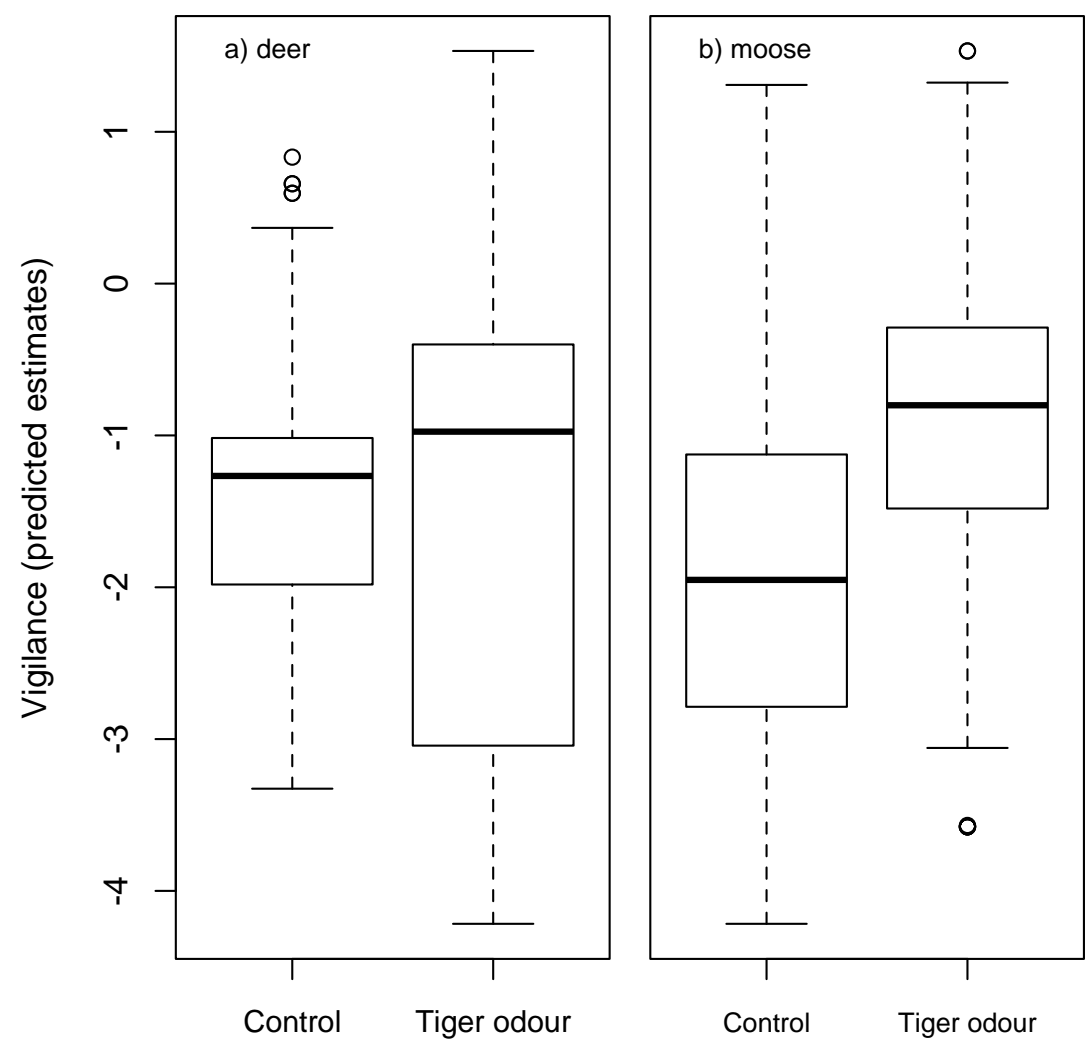

Figure 6. Predicted effects from a model accounting for days of camera activity of predator odour treatment on vigilance behaviour in a) roe deer and b) moose. Effects of treatment differed significantly between species, with moose showing a stronger response than roe deer, though the strength of responses to predator odour within species was not statistically significant

\section{Discussion}

Predator cues alter the incidence of prey species in a landscape, which is likely to have cascading effects on population dynamics throughout the system in line with hypotheses based on the "landscape of fear" (Suraci et al., 2016). Predator cues reduce prey species incidence in areas where predation risk is perceived as high: but prey species do continue to use high risk areas, albeit at lower levels. Understanding how behaviour changes where they do exist in those landscapes is important to gain a fuller 
picture of the effects of predation risk on individual level fitness and population dynamics. In this study we tested the effects of visual and olfactory cues on ungulate vigilance and feeding behaviour tradeoffs, and show no significant changes in either vigilance or feeding behaviour according to predator-cue treatment, contrary to our hypotheses and previous work showing increased vigilance at the expense of feeding in a number of prey species (Creel et al., 2014; Cremona et al., 2014; Beauchamp, 2015; Olson et al., 2015; Eccard et al., 2017). The familiarity of the predator also had no effect on ungulate behavior. We suggest that these results indicate that when prey animals exist in high risk environments (perhaps due to constraints associated with dispersal, or food patch availability), they may display higher selectivity in cue use (i.e. ignoring cues that may be inaccurate) in order to maximise energy intake (Lima and Bednekoff, 1999; Eccard et al., 2017). Additionally, our results reveal differences in how species (roe deer and moose) respond towards predator cues, potentially because body size may effect on how species respond to predation risk (Rogers, 2016; Venter et al., 2017).

\section{Ungulates did not reduce feeding and increase vigilance in the presence of predator cues}

Prey animals use cues within their environment to inform their time allocation to antipredator and other behaviours (McCoy et al., 2012). Based on this, we expected that in the presence of predator cues, ungulates would increase their time spent vigilant, and decrease time spent foraging, in order to maximise survival in a perceived high risk environment. However, we found that roe deer and moose vigilance and feeding behaviours were not affected by either visual or olfactory cues from predators (Figure 4). There are a number of potential explanations for this surprising lack of response to predator cues, that we will consider in turn: a) habituation to uninformative cues is important, b) ungulates may rely more heavily on other cue types, such as auditory cues, or cues in combination, and c) constraints on dispersal resulting in prey forced to remain in high risk food patches and continued prioritization of feeding over vigilance.

First, it is possible that ungulates habituated to the cues presented over time as they learned that the cue was not actually associated with a live predator and did not pose a real threat. Using up to date and accurate information is essential since as suggested by (Karban et al., 2016) it becomes more costly to keep responding to unreliable cues, responding correctly to precise information enhances animal fitness. Our visual cue model accounted for the length of treatment and showed no effect of how long the treatment was deployed, where we might have expected to see a stronger response initially which declined when animals habituated. We, therefore, cannot conclusively say that this is why we see no overall effect of predator cues on behavior in response to visual cues. However, in the context of the olfactory cue, investment in both vigilance and feeding behaviours were significantly predicted by the length of time (days) the camera and treatment had been in place. The strong effect of length of treatment in the odour treatment is essential; it means that they stopped responding once the cue was out of date. This is strongly adaptive; animals do not want to keep using cues that are out of date because then they are wasting opportunities and energy based on wrong information (Karban et al., 2016). Perhaps they are choosier and more discriminatory in how they use cues to alter behaviours related to energy use/consumption, similar to what suggested by (Venter et al., 2006) that different animals respond differently to different threats (predator odour cues included). 
Second, cues that influence habitat use and behaviour may be different; perhaps ungulates rely more on auditory cues, which may contain more accurate and up-to-date information, to adjust their behaviour. We think that we were not able to see the effect because (from the previous submitted study) we saw that these species are already using the landscape differently, so perhaps it might be that those using these areas have already adjusted their behaviours. Venter et al. (2017) suggested that ungulates depend less on visual cues when searching for food (relative to movement behaviors), possibly because it is easier to incorporate auditory cues while foraging with head down, than visual cues, which require the cessation of foraging to lift the head. Auditory cues may also be more likely to be accurate and up-to-date than olfactory cues (Shelton and Kumar, 2010). The effectiveness of olfactory/chemical cues varies with different factors such as weather, seasons, the frequency of use, amount of concentration, and food availability (Elmeros et al., 2011). Another reason might be odour cues might be less effective during harsh winter which characterizes the study area for most parts of the year. To make these cues more effective we in the future we suggest similar to (Knapp et al., 2004; Andreassen et al., 2005) that they should be used in combination with another cue at the same area to pose more risk to the area.

\section{Ungulates did not respond differently to novel/familiar predator cues}

The introduction of a novel predator in an area can have a significant impact on prey species, particularly if prey species do not respond appropriately to novel predator cues, or if there is a learning period (Dunlop-Hayden and Rehage, 2011; Polo-Cavia and Gomez-Mestre, 2014; Carthey et al., 2017). Given that in a previous study (submitted) in the same system novel predator visual cues influenced the incidence of prey species (incidence was more strongly predicted by familiar predator cue presence), we predicted that ungulates might similarly respond less strongly behaviourally to cues from a novel predator (Amur tiger) than to cues from a familiar one (brown bear) (Smith et al., 2008; Saxon-Mills et al., 2018). However, our results show no difference in the amount of time spent vigilant or feeding between the two predator cues treatments (tiger and bear visual cues), i.e., ungulates showed the same lack of response to both novel and familiar predator cues. This is different from what would have normally expected that ungulates (roe deer in this case) would have responded strongly to at least native bear cues and less to a novel tiger cue; but this result is similar to a study showing that mosquitos and flagfish failed to differentiate a chemical cue that comes from a novel predator (Cichlid) (Dunlop-Hayden and Rehage, 2011). It is possible that the fine-scale differentiation of native and novel predators depends on specific cues used by such prey (Dunlop-Hayden and Rehage, 2011), or potentially cues in combination (for example visual + chemical at the same place): Amo et al. (2004) also revealed that lizard increase more the antipredator behavior once exposed to combined cues (visual and chemical) of their snake predator might respond well to cues once they are combined. As well, Elmeros et al. (2011) found that chemical cues did don't repel deer unless integrated directly within the food.

\section{Ungulates did not respond differently to novel/familiar predator cues}

The olfactory predator cue had a significant interactive effect with ungulate species on time allocation on vigilance behaviour, driven by roe deer being more vigilant than moose under control conditions, but having a reduced response to the predator treatment, tiger odour (Figure 5a). We also observed a significant interactive effect of 
treatment and species on time investment on feeding behavior (Figure 5b). It is necessary for prey to allocate time wisely for feeding in order to avoid predation risk at the same avoiding the effect of staying vigilant (e.g., poor fitness, malnourishment) (Lima and Bednekoff, 1999). It was primarily driven by the difference of feeding rate between roe deer and moose at the control treatment, with moose showing a significant lower feeding rate at the control treatment (Figure 7).
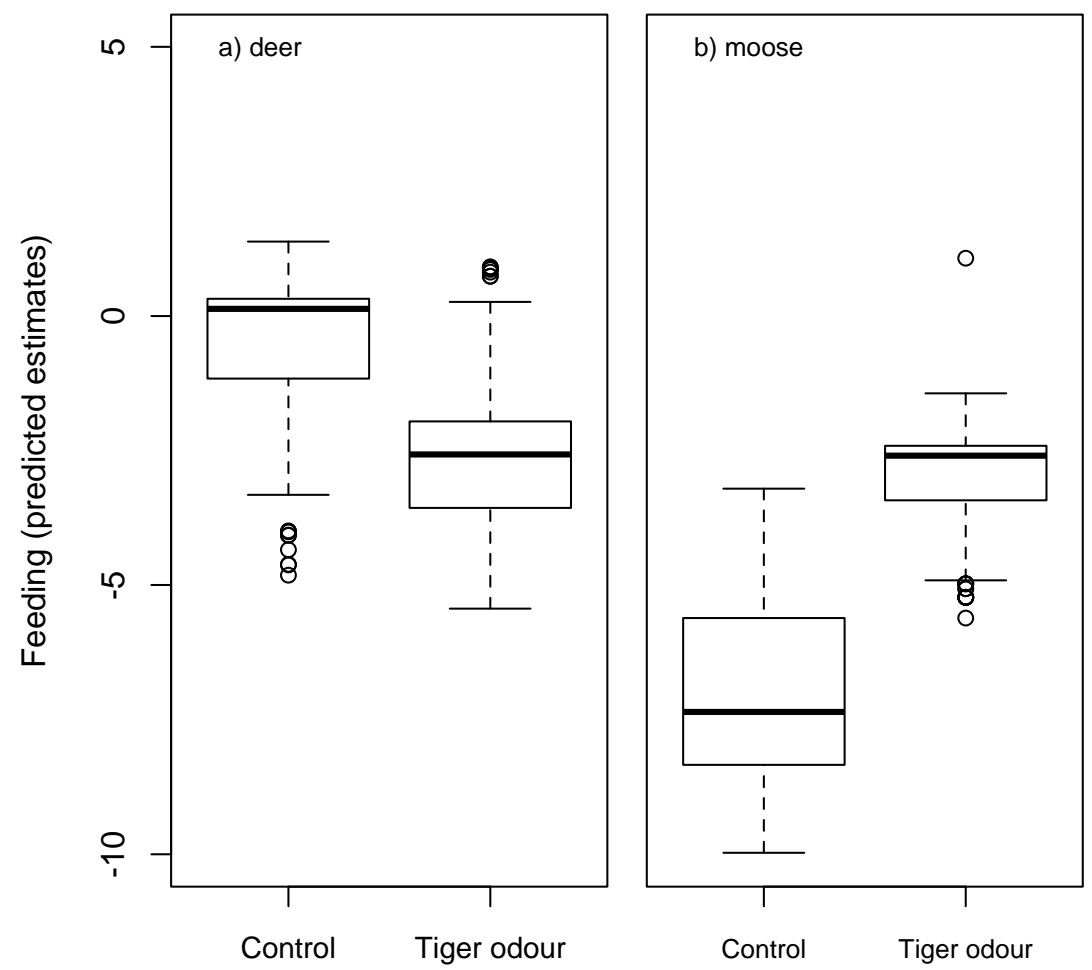

Figure 7. Predicted effects from a model accounting for days of camera activity of predator odour treatment on feeding in a) roe deer and b) moose. Effects of treatment differed significantly between species, with moose showing a significantly lower feeding rate under control treatment than roe deer; the responses to predator odour within species were not statistically significant

Nevertheless, treatment showed no significant effects within-species, partly may be due to the differences in the sense of odour cue perception (Padodara and Jacob, 2014) within these two species. It is possible that species like roe deer, due to their higher vulnerability to a greater number of potential predators (Rogers, 2016), are more vigilant under any circumstances, with the predator cue evoking a lessened response given that they are already at a reasonably high level of vigilance (beyond which, the benefits of increased vigilance may be minimal). Conversely, the stronger response of moose was surprising, since we would expect larger species to be less responsive to risk compared to those of smaller body size (Riginos, 2015), because large body species are a) less likely to be targeted by predators, and b) affected more by lack of food availability than predation risk. Our results emphases the importance of considering different prey species separately when investigating the effects of predation risk and cue use, as ecological and life history differences are likely to contribute to different outcomes of risk. 


\section{Conclusions}

We have successfully shown that both familiar (brown bear) and novel (Amur tiger) cues have no significant influence on ungulates (roe deer and moose) vigilance and foraging behaviors in our study system. Also, our results demonstrate that when prey animals occur in a fearful environment due to limitations of factors like food availability, mating, and dispersal; they display selectivity or even ignore cue use so as to maximise energy intake (Lima and Bednekoff, 1999; Eccard et al., 2017). Likewise, our results tell the differences in how species respond towards predator risk, that small body size animals (roe deer) are potentially at high risk from various predators compared to large size (moose) which are mostly limited by food (foraging) (Rogers, 2016; Venter et al., 2017). Our results also indicate that due to differences in historical background, it is essential to consider each species differently when considering predation risk or cue use effects of different prey species. We further recommend that in the future studies regarding cues can involve a combination of cues (example; visual and order) at the same location to increase predation risk to the animals and see their response. Lastly, to our best level of understanding, this is the first study to lay out the foundation on the ecological influences of captive Amur tiger on prey behaviors in the wild environment.

Acknowledgements. This work was funded by the Fundamental Research Funds for the Central Universities (2572017PZ14), the fund from the National Key Programme of Research and Development, Ministry of Science and Technology (2016YFC0503200), and National Nature Science Foundation of China (NSFC 31872241; 31572285). We thank Benjamin Jarrett for providing his helpful comments on statistical methodology, Bao Heng, Zhai Penghu and Liu Yan for their support during fieldwork. Lastly, thanks to the entire Hanma National Nature Reserve staff for their outstanding support during fieldwork. This work is part of the principal author PhD work.

\section{REFERENCES}

[1] Altmann, J. (1974): Observational study of behavior: sampling methods. - Behaviour 49(3): 227-266.

[2] Amo, L., López, P., Martín, J. (2004): Wall lizards combine chemical and visual cues of ambush snake predators to avoid overestimating risk inside refuges. - Animal Behaviour 67(4): 647-653.

[3] Andreassen, H. P., Gundersen, H., Storaas, T. (2005): The effect of scent-marking, forest clearing, and supplemental feeding on moose-train collisions. - The Journal of wildlife management 69(3): 1125-1132.

[4] Apfelbach, R., Blanchard, C. D., Blanchard, R. J., Hayes, R. A., McGregor, I. S. (2005): The effects of predator odors in mammalian prey species: a review of field and laboratory studies. - Neuroscience \& Biobehavioral Reviews 29(8): 1123-1144.

[5] Banks, P. B., Dickman, C. R. (2007): Alien predation and the effects of multiple levels of prey naiveté. - Trends in ecology \& evolution 22(5): 229-230.

[6] Beauchamp, G. (2015): Animal vigilance: monitoring predators and competitors. Academic Press.

[7] Blumstein, D. T. (2003): Flight-initiation distance in birds is dependent on intruder starting distance. - The Journal of Wildlife Management: 852-857.

[8] Blumstein, D. T. (2006): The multipredator hypothesis and the evolutionary persistence of antipredator behavior. - Ethology 112(3): 209-217. 
[9] Blumstein, D. T., Daniel, J. C., Griffin, A. S., Evans, C. S. (2000): Insular tammar wallabies (Macropus eugenii) respond to visual but not acoustic cues from predators. Behavioral Ecology 11(5): 528-535.

[10] Bridges, C. M. (2002): Tadpoles balance foraging and predator avoidance: effects of predation, pond drying, and hunger. - Journal of Herpetology: 627-634.

[11] Brook, L. A., Johnson, C. N., Ritchie, E. G. (2012): Effects of predator control on behaviour of an apex predator and indirect consequences for mesopredator suppression. Journal of applied ecology 49(6): 1278-1286.

[12] Brown, G. E., Cowan, J. (2000): Foraging trade-offs and predator inspection in an Ostariophysan fish: switching from chemical to visual cues. - Behaviour 137(2): 181195.

[13] Brown, J. S. (1999): Vigilance, patch use and habitat selection: foraging under predation risk. - Evolutionary Ecology Research 1(1): 49-71.

[14] Brown, J. S., Kotler, B. P. (2004): Hazardous duty pay and the foraging cost of predation. - Ecology letters 7(10): 999-1014.

[15] Carthey, A. J., Bucknall, M. P., Wierucka, K., Banks, P. B. (2017): Novel predators emit novel cues: a mechanism for prey naivety towards alien predators. - Scientific reports 7(1): 16377.

[16] Chamaillé-Jammes, S., Malcuit, H., Le Saout, S., Martin, J.-L. (2014): Innate threatsensitive foraging: black-tailed deer remain more fearful of wolf than of the less dangerous black bear even after 100 years of wolf absence. - Oecologia 174(4): 11511158 .

[17] Creel, S., Christianson, D. (2008): Relationships between direct predation and risk effects. - Trends in Ecology \& Evolution 23(4): 194-201.

[18] Creel, S., Schuette, P., Christianson, D. (2014): Effects of predation risk on group size, vigilance, and foraging behavior in an African ungulate community. - Behavioral Ecology 25(4): 773-784.

[19] Cremona, T., Crowther, M. S., Webb, J. K. (2014): Variation of prey responses to cues from a mesopredator and an apex predator. - Austral ecology 39(7): 749-754.

[20] Dunlop-Hayden, K., Rehage, J. S. (2011): Antipredator behavior and cue recognition by multiple Everglades prey to a novel cichlid predator. - Behaviour 148(7): 795-823.

[21] Eccard, J. A., Liesenjohann, T. (2008): Foraging decisions in risk-uniform landscapes. PLoS One 3(10): e3438.

[22] Eccard, J. A., Meißner, J. K., Heurich, M. (2017): European roe deer increase vigilance when faced with immediate predation risk by Eurasian Lynx. - Ethology 123(1): 30-40.

[23] Elmeros, M., Winbladh, J. K., Andersen, P. N., Madsen, A. B., Christensen, J. T. (2011): Effectiveness of odour repellents on red deer (Cervus elaphus) and roe deer (Capreolus capreolus): a field test. - European journal of wildlife research 57(6): 1223-1226.

[24] Fischer, S., Oberhummer, E., Cunha-Saraiva, F., Gerber, N., Taborsky, B. (2017): Smell or vision? The use of different sensory modalities in predator discrimination. Behavioral Ecology and Sociobiology 71(10): 143.

[25] Guo, K., Liu, H., Bao, H., Hu, J., Wang, S., Zhang, W., Zhao, Y., Jiang, G. (2017): Habitat selection and their interspecific interactions for mammal assemblage in the Greater Khingan Mountains, northeastern China. - Wildlife Biology: 00261.

[26] Heijtel, M. G., van Hooft, W. (2014): Camera trapping the wolf (Canis lupus) population in Białowieża Primeval Forest, Poland.

[27] Hemmi, J. M., Pfeil, A. (2010): A multi-stage anti-predator response increases information on predation risk. - Journal of Experimental Biology 213(9): 1484-1489.

[28] Hernández, L., Laundré, J. W. (2005): Foraging in the 'landscape of fear'and its implications for habitat use and diet quality of elk Cervus elaphus and bison Bison bison. - Wildlife Biology 11(3): 215-220. 
[29] Karban, R., Orrock, J. L., Preisser, E. L., Sih, A. (2016): A comparison of plants and animals in their responses to risk of consumption. - Current opinion in plant biology 32: $1-8$.

[30] Kats, L. B., Dill, L. M. (2016): The scent of death: Chemosensory assessment of predation risk by prey animals. - Écoscience 5(3): 361-394.

[31] Knapp, K. K., Yi, X., Oakasa, T., Thimm, W., Hudson, E., Rathmann, C. (2004): Deervehicle crash countermeasure toolbox: a decision and choice resource. http://www.deercrash.org/toolbox/finalreport.pdf.

[32] Krivoruchko, K. (2011): Spatial statistical data analysis for GIS users. - Esri Press Redlands.

[33] Kuijper, D. P., Verwijmeren, M., Churski, M., Zbyryt, A., Schmidt, K., Jędrzejewska, B., Smit, C. (2014): What cues do ungulates use to assess predation risk in dense temperate forests? - PLoS One 9(1): e84607.

[34] Laundré, J. W., Hernández, L., Altendorf, K. B. (2001): Wolves, elk, and bison: reestablishing the" landscape of fear" in Yellowstone National Park, USA. - Canadian Journal of Zoology 79(8): 1401-1409.

[35] Li, C., Yang, X., Ding, Y., Zhang, L., Fang, H., Tang, S., Jiang, Z. (2011): Do Pere David's deer lose memories of their ancestral predators? - PLoS One 6(8): e23623.

[36] Lima, S. L., Bednekoff, P. A. (1999): Temporal variation in danger drives antipredator behavior: the predation risk allocation hypothesis. - The American Naturalist 153(6): 649-659.

[37] Margulis, S. (2016): Sampling Animal Behavior: Animal Behavior Society Workshop. Available online.

[38] Martin, P., Bateson, P. P. G., Bateson, P. (1993): Measuring behaviour: an introductory guide. - Cambridge University Press.

[39] McCoy, M. W., Touchon, J. C., Landberg, T., Warkentin, K. M., Vonesh, J. R. (2012): Prey responses to predator chemical cues: disentangling the importance of the number and biomass of prey consumed. - PloS one 7(10): e47495.

[40] Meng, X., Yang, Q., Feng, Z., Xu, H., Perkins, G. C., Feng, J., Zhang, D. (2008): Seasonal behavioral patterns of captive alpine musk deer (Moschus sifanicus): Rut and pre-rut comparisons. - Biologia 63(4): 594-598.

[41] Nersesian, C. L., Banks, P. B., McArthur, C. (2012): Behavioural responses to indirect and direct predator cues by a mammalian herbivore, the common brushtail possum. Behavioral Ecology and Sociobiology 66(1): 47-55.

[42] Noell, S. (2013): Effects of brown bear (Ursus arctos) odour on the patch choice and behaviour of different ungulate species. - Swedish University of Agricultural Sciences.

[43] Olson, R. S., Haley, P. B., Dyer, F. C., Adami, C. (2015): Exploring the evolution of a trade-off between vigilance and foraging in group-living organisms. - Royal Society open science 2(9): 150135.

[44] Padodara, R., Jacob, N. (2014): Olfactory Sense in Different Animals. - Indian Journal of Veterinary Science 2: 1-14.

[45] Palacios, M., Warren, D. T., McCormick, M. I. (2016): Sensory cues of a top-predator indirectly control a reef fish mesopredator. - Oikos 125(2): 201-209.

[46] Polo-Cavia, N., Gomez-Mestre, I. (2014): Learned recognition of introduced predators determines survival of tadpole prey. - Functional Ecology 28(2): 432-439.

[47] Riginos, C. (2015): Climate and the landscape of fear in an African savanna. - Journal of Animal Ecology 84(1): 124-133.

[48] Rogers, H. (2016): Influence of temperature and predation risk on herbivore micro habitat choice in a South African savanna. - Swedish University of Agricultural Sciences, Epsilon Archive for Student projects.

[49] Saxon-Mills, E. C., Moseby, K., Blumstein, D. T., Letnic, M. (2018): Prey naïveté and the anti-predator responses of a vulnerable marsupial prey to known and novel predators. - Behavioral Ecology and Sociobiology 72(9): 151. 
[50] Shelton, J., Kumar, G. P. (2010): Comparison between auditory and visual simple reaction times. - Neuroscience \& Medicine 1(1): 30-32.

[51] Sih, A., Bolnick, D. I., Luttbeg, B., Orrock, J. L., Peacor, S. D., Pintor, L. M., Preisser, E., Rehage, J. S., Vonesh, J. R. (2010): Predator-prey naïveté, antipredator behavior, and the ecology of predator invasions. - Oikos 119(4): 610-621.

[52] Smith, G. R., Boyd, A., Dayer, C. B., Winter, K. E. (2008): Behavioral responses of American toad and bullfrog tadpoles to the presence of cues from the invasive fish, Gambusia affinis. - Biological Invasions 10(5): 743-748.

[53] Suraci, J. P., Clinchy, M., Dill, L. M., Roberts, D., Zanette, L. Y. (2016): Fear of large carnivores causes a trophic cascade. - Nature Communications 7: 10698.

[54] Team, R. C. (2015): R: A language and environment for statistical computing [Internet]. - Vienna, Austria: R Foundation for Statistical Computing; 2015.

[55] Venter, O., Brodeur, N. N., Nemiroff, L., Belland, B., Dolinsek, I. J., Grant, J. W. (2006): Threats to endangered species in Canada. - AIBS Bulletin 56(11): 903-910.

[56] Venter, J. A., Prins, H. H., Mashanova, A., Slotow, R. (2017): Ungulates rely less on visual cues, but more on adapting movement behaviour, when searching for forage. PeerJ 5: e3178.

[57] Wang, Q., Liu, D., Holyoak, M., Jia, T., Yang, S., Liu, X., Kong, X., Jiang, G. (2018): Innate preference for native prey and personality implications in captive Amur tigers. Applied Animal Behaviour Science 210: 95-102.

[58] Wikenros, C., Jarnemo, A., Frisén, M., Kuijper, D. P., Schmidt, K. (2017): Mesopredator behavioral response to olfactory signals of an apex predator. - Journal of ethology 35(2): 161-168.

[59] Zhai Penghui, L. Y., Li, Z. S. (2015): The Current Situation and Evaluation of the Biodiversity of Hanma National Nature Reserve. - China Academic Journal Electronic House. 